\title{
Heats of Formation of Diborane and Pentaborane
}

\author{
Edward J. Prosen, Walter H. Johnson, and Florence Y. Pergiel
}

\begin{abstract}
The heats of formation of diborane and pentaborane have been determined by measurements of the heats of decomposition into amorphous boron and hydrogen in a calorimeter. The heats of formation at $25^{\circ} \mathrm{C}$, from amorphous boron and hydrogen, are $6.73 \pm 0.52 \mathrm{kcal} /$ mole for diborane (gas) and $12.99 \pm 0.39$ for pentaborane (gas).
\end{abstract}

\section{Introduction}

In order to ascertain the bond energy relations in the boron hydrides, precise values of the heats of formation of these substances from the elements are needed. Diborane, $\mathrm{B}_{2} \mathrm{H}_{6}$, and pentaborane, $\mathrm{B}_{5} \mathrm{H}_{9}$, were chosen for investigation as two of the simplest members of this class of compounds.

The measurements reported in this paper were made in 1948 but have not been previously published. No value for the heat of formation of pentaborane was available at that time. The value for the heat of formation of diborane given by Roth and Börger, $-44 \mathrm{kcal} / \mathrm{mole},[1,2]^{1}$ was based on measurements of the heat of hydrolysis of diborane to boric acid, the heat of combustion of boron to boric oxide, and the heat of solution of boric oxide. This value was very uncertain because it depended directly upon the heat of combustion of elemental boron, a quantity which could not be determined with any precision. However, it was found that diborane and pentaborane could be decomposed quantitatively and rapidly at $600^{\circ} \mathrm{C}$ into amorphous boron and gaseous hydrogen. Hence this decomposition reaction could be employed calorimetrically to give values of the heats of formation of diborane and pentaborane independent of the value for the heat of combustion of boron.

\section{Experimental Procedure}

\subsection{Materials}

The diborane and pentaborane samples were obtained from the Naval Research Laboratory, Washington, D. C., through the courtesy of R. R. Miller. A similar sample of diborane supplied to the Ohio State University was found by the cryoscopic method to have a purity of 99.95 mole percent [3].

The pentaborane was produced by the fractional pyrolysis of diborane. A sample of the same lot supplied to the Ohio State University was found by the cryoscopic method to have a purity of 99.97 mole percent [4]. Analysis by the mass spectrometer showed no impurities other than boron hydrides with none heavier than $\mathrm{B}_{5} \mathrm{H}_{9}[5]$.

\subsection{Apparatus}

The calorimeter was of the isothermal-jacket type; the jacket temperature was maintained constant within $\pm 0.001^{\circ} \mathrm{C}$ during each experiment. Details of the calorimeter assembly have been described in previous reports from this laboratory $[6,7]$.

\footnotetext{
1 Figures in brackets indicate the literature references at the end of this paper.
}

The calorimetric vessel used for the decomposition of diborane and pentaborane is shown in figure 1 . It consisted essentially of a quartz tube (A) upon which was wound a nichrome wire heating coil (B) surrounded by a silver radiation shield (C) and a vacuum jacket (D). The heating coil had a total resistance of $190 \mathrm{ohms}$ and was tapped $(\mathrm{E})$ so that the upper portion had a resistance of 127 ohms. Quartz wool plugs (F) were inserted in the tube above and below the heating coil to retain the solid products within the heated zone. The exit vapors were carried out through the glass helix $(\mathrm{G})$ to cool them to the calorimeter temperature.

Calorimeter temperatures were determined by means of a platinum resistance thermometer in conjunction with a Mueller bridge. The quantity of electrical energy was determined from the current, voltage, and time of current flow. The current and voltage were determined by means of a White double

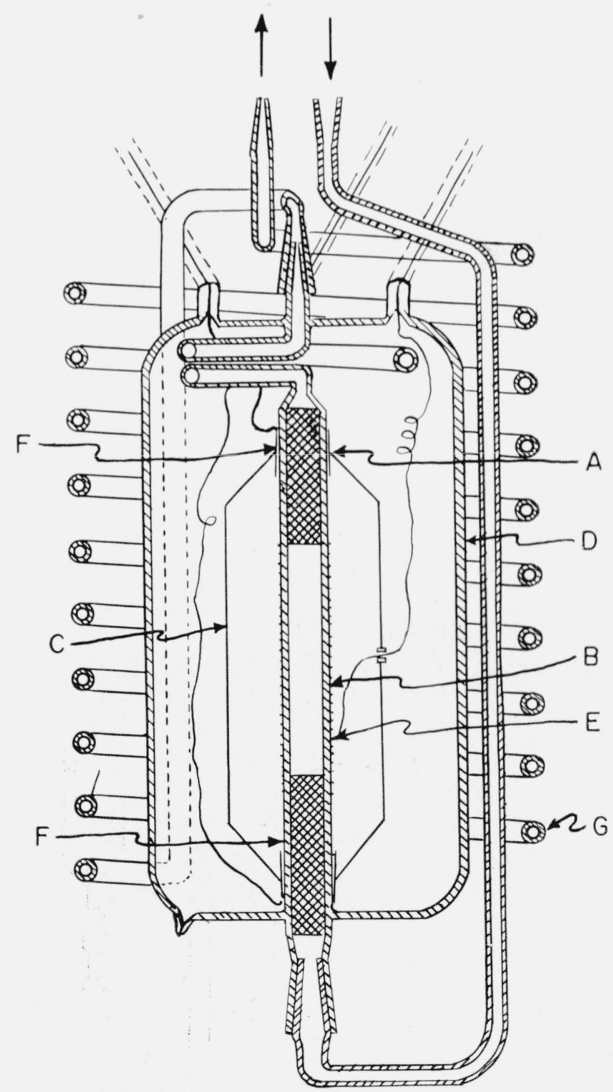

FIGURE 1. Calorimetric reaction vessel. 
potentiometer from measurements of the potential drop across appropriate standard resistors included in the power circuit [8]. Timing of the experiments was done by reference to standard seconds-signals produced at the National Bureau of Standards. All equipment was calibrated in terms of standards maintained at the Bureau.

\subsection{Procedure}

\section{a. Reaction Experiments}

(1) Diborane. The gas train used for the diborane decomposition experiments is shown in figure 2 . The diborane was contained in a steel cylinder fitted with a needle valve and connected to the system through a flowmeter and a mercury float valve. Before each experiment the cylinder was immersed in liquid nitrogen, and traces of hydrogen (produced by slow decomposition of diborane into higher boranes) were removed by evacuation. After removal of the hydrogen the valve was closed and dry ice was substituted for the liquid nitrogen; at the temperature of dry ice, the vapor pressure of diborane is approximately 2 atm and the vapor pressures of the higher boranes are negligible. Helium was passed through the system at a constant rate throughout the experiment. It was purified by passing successively over copper oxide at $600^{\circ} \dot{\mathrm{C}}$, ascarite, magnesium perchlorate, and phosphorus pentoxide before it entered the system.
Temperatures were observed at 2-min intervals during a 20-min "fore" rating period. At the end of this period the current was switched from an external "spill" resistor (having the same resistance as the heater) into the upper portion of the calorimetric vessel. After a warm-up period of $2 \mathrm{~min}$ the needle valve was opened, which permitted the diborane to pass into the vessel. The flow of diborane was cut off after $16 \mathrm{~min}$ and the float valve closed. Four minutes later the current was swtched to pass through both portions of the heater; this completed the decomposition of the polymerized material usually formed near the lower end of the upper portion of the heater. By means of appropriate resistors in the circuit, the current was nearly constant in both cases. During this time readings of current and voltage were made on alternate minutes, and temperature readings were made at 1-min intervals. When the desired calorimeter temperature was obtained the electric current was discontinued. Temperature measurements were continued at 1-min intervals until thermal equilibrium was reestablished, after which observations were made at 2 -min intervals during a 20 -min "after" rating period.

The gas mixture of helium and hydrogen passed out of the calorimeter through a trap cooled in liquid nitrogen, a copper oxide furnace maintained at $600^{\circ} \mathrm{C}$, and a weighed absorption tube containing magnesium perchlorate and phosphorus pentoxide.

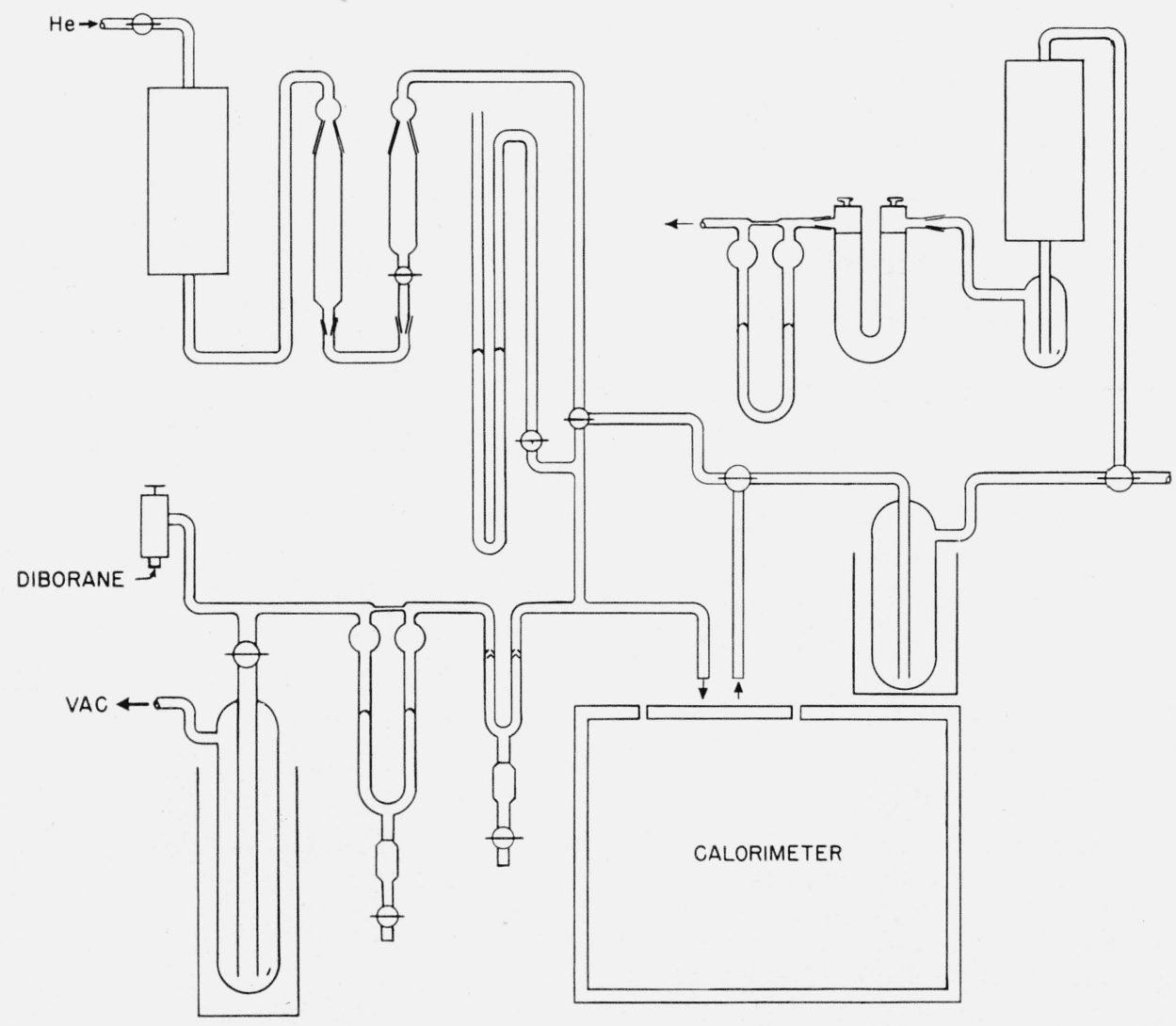

Figure 2. Gas train used in thermal decomposition of diborane. 


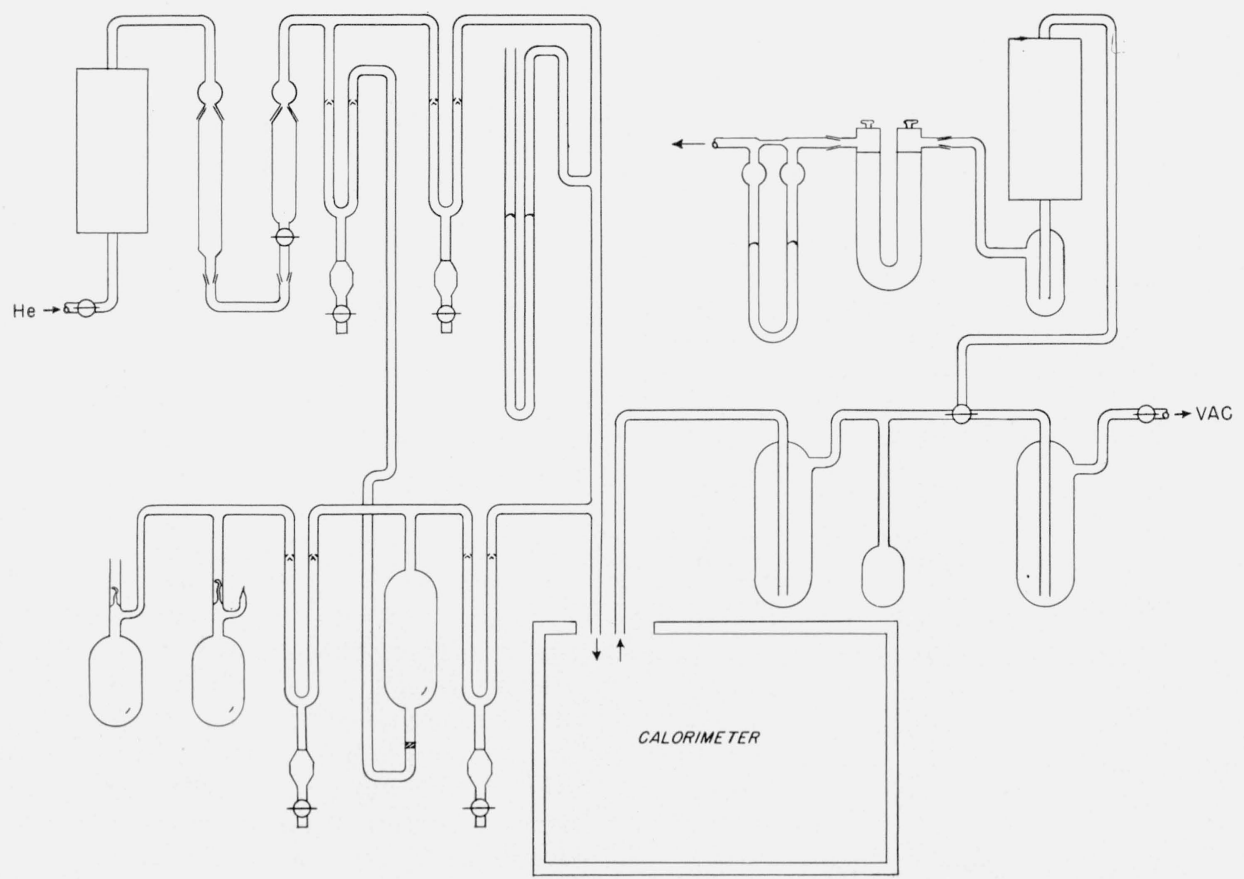

FIGURE 3. Gas train for use in decomposition of pentaborane $\left(\mathrm{B}_{5} \mathrm{H}_{9}\right)$.

The trap was included as a safety measure, to prevent the diborane from reaching the furnace in the event of incomplete decomposition. No material was collected in the trap in any of these experiments.

The quantity of reaction was determined from the amount of hydrogen which was burned in the furnace and collected in the absorption tube as water.

(2) Pentaborane. The gas train used in the experiments with pentaborane is shown in figure 3. The pentaborane was inclosed in an internal breakoff ampoule. For each experiment the system was evacuated and a portion of the pentaborane transferred into the bubbling vessel. 'The experiments were carried out in the same manner as with diborane except that purified helium was bubbled through the pentaborane at $0^{\circ} \mathrm{C}$ in order to carry it into the calorimetric vessel. After each experiment, the remainder of the pentaborane in the bubbler, as well as that remaining in the original ampoule, was transferred to a second ampoule and sealed in vacuum.

\section{b. Calibration Experiments}

The calibration experiments were performed in exactly the same manner and using the same system as with the decomposition experiments except for omission of the boron hydride. Because the system used for pentaborane differed slightly from that used for diborane, a separate series of calibration experiments was performed.

\section{Results}

The results of the calibration experiments for the diborane system are given in table 1 in which $E$ corresponds to the electrical energy added to the system, $\Delta R c$ the increase in resistance of the platinum thermometer, and $E_{s}=E / \Delta R c$, the energy equivalent of the system.

The results of the diborane decomposition experiments are given in table 2, where $q$ is the total energy absorbed by the system and is given by the following relationship:

$$
(\Delta R c)\left(E_{s}\right)=q .
$$

This value of $q$ when corrected for $q_{g}$, the correction calculated from the heat capacities of the gases involved, and subtracted from $E$, the electrical

TABLE 1.-Results of the electrical calibration experiments on the diborane system

\begin{tabular}{|c|c|c|c|}
\hline $\begin{array}{c}\text { Experi- } \\
\text { ment }\end{array}$ & $E$ & $\Delta R_{c}$ & $E_{s}$ \\
\hline $\begin{array}{l}1 \\
2 \\
3 \\
4 \\
5\end{array}$ & $\begin{array}{c}j \\
49480.9 \\
50329.8 \\
49804.4 \\
51630.9 \\
49551.6\end{array}$ & $\begin{array}{c}\text { Ohm } \\
0.381239 \\
.387803 \\
.383708 \\
.397799 \\
.381761\end{array}$ & $\begin{array}{l}\text { j/ohm } \\
129790 \\
129782 \\
129798 \\
129791 \\
129797\end{array}$ \\
\hline \multicolumn{3}{|c|}{$\begin{array}{l}\text { Mean } \\
\text { Standard deviation of the mean }\end{array}$} & $\begin{array}{r}129792 \\
\quad \pm 3\end{array}$ \\
\hline
\end{tabular}

TABLE 2. Results of the diborane decomposition experiments

\begin{tabular}{|c|c|c|c|c|c|c|c|}
\hline $\begin{array}{l}\text { Exper- } \\
\text { iment }\end{array}$ & $E$ & $\Delta R_{c}$ & $q$ & $q_{g}$ & $q_{c}$ & $B_{2} H_{6}$ & $\left(25^{\circ} \stackrel{\mathrm{C}}{-\Delta H}\right)$ \\
\hline $\begin{array}{l}1 \\
2 \\
3 \\
4 \\
4 \\
5\end{array}$ & $\begin{array}{c}j \\
51311.2 \\
48536.9 \\
48557.9 \\
49008.7 \\
48704.1\end{array}$ & $\begin{array}{c}\text { Ohm } \\
0.397528 \\
.379034 \\
.377216 \\
.379105 \\
.376538\end{array}$ & $\begin{array}{c}j \\
51596.0 \\
49195.6 \\
48959.6 \\
49204.8 \\
48871.6\end{array}$ & 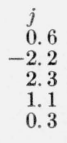 & $\begin{array}{c}j \\
-284.2 \\
-660.9 \\
-399.4 \\
-195.0 \\
-167.2\end{array}$ & $\begin{array}{c}\text { Mole } \\
0.010206 \\
.021851 \\
.015966 \\
.007213 \\
.005444\end{array}$ & $\begin{array}{c}\text { kj/mole } \\
27.85 \\
30.25 \\
25.02 \\
27.04 \\
30.71\end{array}$ \\
\hline \multicolumn{7}{|c|}{$\begin{array}{l}\text { Mean } \\
\text { Standard deviation of the mean }\end{array}$} & $\begin{array}{r}28.17 \\
\pm 1.05\end{array}$ \\
\hline
\end{tabular}


energy added to the system, yields $q_{c}$, the energy absorbed by $m$ moles of reaction, or:

$$
E-\left(q-q_{g}\right)=q_{c} .
$$

The heat of reaction at $25^{\circ} \mathrm{C}$ is then given by the ratio of $q_{c}$ to $m$, or:

$$
q_{c} / m=\Delta H \text { joules } / \text { mole. }
$$

To convert to the conventional thermochemical calorie, the following relationship was used:

$$
1 \text { calorie }=4.1840 \text { joules. }
$$

The results of the calibration experiments on the pentaborane system and the results of the pentaborane decomposition experiments are given in tables 3 and 4 , respectively.

\begin{tabular}{|c|c|c|c|}
\hline $\begin{array}{l}\text { Experi- } \\
\text { ment }\end{array}$ & $E$ & $\Delta R_{c}$ & $E_{\mathrm{s}}$ \\
\hline $\begin{array}{l}1 \\
2 \\
3 \\
4\end{array}$ & $\begin{array}{c}j \\
48651.0 \\
49904.1 \\
48058.8 \\
49314.9\end{array}$ & $\begin{array}{c}\text { Ohm } \\
0.374654 \\
.384457 \\
.370289 \\
.379834\end{array}$ & $\begin{array}{l}\text { j/ohm } \\
129856 \\
129804 \\
129787 \\
129833\end{array}$ \\
\hline $\begin{array}{l}5 \\
6 \\
7 \\
8\end{array}$ & $\begin{array}{l}48547.3 \\
48495.9 \\
48657.3 \\
48529.6\end{array}$ & $\begin{array}{l}.374191 \\
.373680 \\
.374996 \\
.373886\end{array}$ & $\begin{array}{l}129739 \\
129779 \\
129754 \\
129798\end{array}$ \\
\hline \multicolumn{3}{|c|}{$\begin{array}{l}\text { Mean } \\
\text { Standard deviation of the mean }\end{array}$} & $\begin{array}{l}129794 \\
\pm 14\end{array}$ \\
\hline
\end{tabular}

TABLE 3. Results of the electrical calibration experiments on the pentaborane system

\begin{tabular}{|c|c|c|c|c|c|c|c|}
\hline $\begin{array}{l}\text { Exper- } \\
\text { iment }\end{array}$ & $E$ & $\Delta R_{c}$ & $q$ & $q_{g}$ & $q_{c}$ & $B_{5} H_{9}$ & $\begin{array}{c}-\Delta H \\
\left(25^{\circ} \mathrm{C}\right)\end{array}$ \\
\hline $\begin{array}{l}1 \\
2 \\
3 \\
4 \\
5 \\
6\end{array}$ & $\begin{array}{c}j \\
49998.5 \\
49709.6 \\
49802.4 \\
49806.8 \\
49709.2 \\
51323.6\end{array}$ & $\begin{array}{c}\text { Ohm } \\
0.386650 \\
.384273 \\
.385107 \\
.385605 \\
.385471 \\
.397303\end{array}$ & $\begin{array}{c}j \\
50185.6 \\
49876.3 \\
49984.6 \\
50049.2 \\
50031.4 \\
51567.5\end{array}$ & $\begin{array}{c}j \\
+0.4 \\
-0.1 \\
+0.2 \\
+1.2 \\
+1.2 \\
+0.8\end{array}$ & $\begin{array}{c}j \\
-186.7 \\
-166.8 \\
-182.0 \\
-241.2 \\
-321.0 \\
-243.1\end{array}$ & $\begin{array}{c}\text { Mole } \\
0.003409 \\
.002889 \\
.003560 \\
.004353 \\
.006037 \\
.004508\end{array}$ & $\begin{array}{l}\mathrm{kj} / \mathrm{mole} \\
54.77 \\
57.74 \\
51.12 \\
55.41 \\
53.17 \\
53.93\end{array}$ \\
\hline \multicolumn{7}{|c|}{$\begin{array}{l}\text { Mean } \\
\text { Standard deviation of the mean }\end{array}$} & $\begin{array}{r}54.36 \\
\pm 0.91\end{array}$ \\
\hline
\end{tabular}

TABLE 4. Results of the pentaborane decomposition experiments

The heats of decomposition obtained for the reactions of decomposition are given by the following equations :

$$
\begin{gathered}
\left.\mathrm{B}_{2} \mathrm{H}_{6}(\text { gas })=2 \mathrm{~B} \text { (solid, amorphous }\right)+3 \mathrm{H}_{2} \text { (gas), } \\
\Delta \mathrm{H}\left(25^{\circ} \mathrm{C}\right)=-6.73 \pm 0.52 \mathrm{kcal} / \mathrm{mole}, \\
\left.\mathrm{B}_{5} \mathrm{H}_{9}(\text { gas })=5 \mathrm{~B} \text { (solid, amorphous }\right)+9 / 2 \mathrm{H}_{2} \text { (gas), } \\
\Delta \mathrm{H}\left(25^{\circ} \mathrm{C}\right)=-12.99 \pm 0.39 \mathrm{kcal} / \mathrm{mole} .
\end{gathered}
$$

The uncertainties assigned have been taken as twice the standard deviation of the mean of the experimental values, combined with reasonable estimates of all known sources of error.

By taking the amorphous form as the reference state of boron and $7.30 \pm 0.10 \mathrm{kcal} / \mathrm{mole}[9]$ for the heat of vaporization of pentaborane, the following heats of formation are obtained:

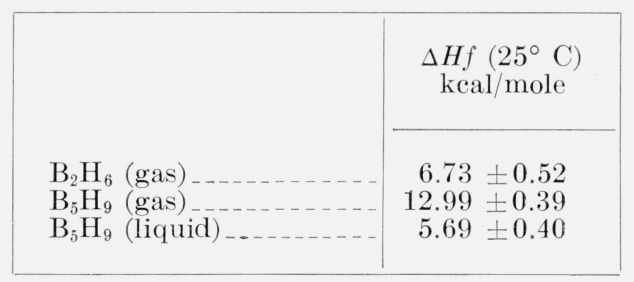

\section{Discussion}

It was not possible to recover the finely divided boron quantitatively from the reaction vessel because of its tendency to adhere to the walls of the vessel as well as to the quartz wool plugs. It was therefore not feasible to obtain an accurate check on the completeness of the decomposition by determining the stoichiometric ratio between the masses of boron and hydrogen. In order to determine the presence of hydrogen, either chemically bound or adsorbed, samples of the boron produced were heated to $700^{\circ} \mathrm{C}$ in vacuum. Although traces of hydrogen were detected in some cases it is not likely that any significant error was introduced in the final result since the quantity of reaction in each case was based upon the mass of hydrogen evolved. Obviously, if all the boron-hydrogen bonds were of the same energy, the heat of decomposition as measured would be independent of the proportion of hydrogen removed in the process. The possibility that an extremely stable hydride was present was ruled out because portions of the residue treated with chlorine at $400^{\circ} \mathrm{C}$ were completely converted to boron trichloride [10]. The Constitution and Microstructure Section of the Bureau examined portions of the residue by X-ray diffraction methods. The absence of a pattern indicated that the boron was in an amorphous form.

In view of this information we conclude that the reaction of decomposition is quantitative and that the only products are amorphous boron and hydrogen. The thermal decomposition is probably the most convenient method for preparation of small quantities of high-purity boron.

\section{References}

[1] W. A. Roth and E. Börger, Ber. [B] $\mathbf{0 0 ,} 48$ (1937).

[2] W. A. Roth, Z. Naturforsch. 1, 574 (1946).

[3] E. M. Carr, J. T. Clarke, and H. L. Johnston, J. Am. Chem. Soc. $\mathbf{1 1}, 740(1949)$.

[4] J. T. Clarke and H. L. Johnston (private communication).

[5] V. H. Dibeler, F. L. Mohler, L. Williamson, and R. M. Reese, J. Research NBS 44, 489 (1950) RP2095.

[6] J. R. Eckman and F. D. Rossini, J. Research NBS 3, 597 (1929) RP111.

[7] E. J. Prosen and F. D. Rossini, J. Research NBS 27, 289 (1941) RP1420.

[8] E. J. Prosen and F. D. Rossini, J. Research NBS 33, 255 (1944) RP1607.

[9] W. H. Evans and D. D. Wagman, (manuscript in preparation).

[10] E. H. Winslow and H. A. Liebhafsky, J. Am. Chem. Soc. 64, 2725 (1942).

Washington, June 29, 1958. 